\title{
Finite Element Method Analysis of Effect of Thickness of Tape-shaped Ti-Ni Shape Memory Alloy on Post-buckling Behavior
}

\author{
Takumi Ishii, ${ }^{1}$ Hiroki Cho, ${ }^{2 *}$ Atsushi Urakawa, ${ }^{1}$ and Takumi Sasaki ${ }^{2}$ \\ ${ }^{1}$ Graduate Student of Environmental Engineering, The University of Kitakyushu, \\ 1-1, Hibikino, Wakamatsu-ku, Kitakyushu, Fukuoka 808-0135, Japan \\ ${ }^{2}$ Faculty of Environmental Engineering, The University of Kitakyushu, \\ 1-1, Hibikino, Wakamatsu-ku, Kitakyushu, Fukuoka 808-0135, Japan
}

(Received March 27, 2020; accepted June 26, 2020)

Keywords: shape memory alloy, Ti-Ni alloy, buckling deformation, FEM analysis, negative stiffness

A tape-shaped Ti-Ni shape memory alloy (SMA) element, which demonstrates superelastic behavior, shows negative stiffness during post-buckling deformation. This characteristic is applied to a passive vibration-free system using a zero-stiffness structure. However, the postbuckling behavior (negative stiffness) of an SMA element can be varied by modifying its dimensions. In this study, the effect of the thickness of a tape-shaped SMA element on its postbuckling behavior is investigated by finite element method (FEM) analysis. The magnitude of the negative stiffness increases with the thickness. Furthermore, the rate of increase of the volume fraction of the martensitic phase before the start of buckling deformation increases with the thickness. From these results, we conclude that the magnitude of negative stiffness during the post-buckling of a tape-shaped SMA element depends on the variation of the volume fraction of the martensitic phase during buckling deformation.

\section{Introduction}

Shape memory alloys (SMAs) are well known as functional materials with the shape memory effect and superelasticity. Since Ti-Ni-based SMAs show an excellent shape memory characteristic and good mechanical properties, ${ }^{(1-3)}$ they are used in medical and industrial fields in, for example, energization actuators ${ }^{(4,5)}$ and heat engines. ${ }^{(6,7)}$ The buckling/postbuckling behavior of Ti-Ni SMA elements memorized to a straight shape has been investigated in the architectural field. Rahman et al. reported the effect of the slenderness ratio $(L / k)$ on the buckling/post-buckling behavior of Ti-Ni SMA columns. ${ }^{(8)}$ Pereiro-Barceló and Bonet proposed a new analytical model of the buckling/post-buckling behavior of Ni-Ti SMA bars. ${ }^{(9)}$ These studies found that Ti-Ni SMA memorized to a straight shape shows negative or quasizero stiffness during post-buckling deformation. Since the deformation of SMA elements can be recovered during the unloading process by superelastic behavior, the negative or quasizero stiffness characteristic can be used repeatedly. Quasi-zero stiffness can be applied to a

*Corresponding author: e-mail: h-cho@kitakyu-u.ac.jp

https://doi.org/10.18494/SAM.2020.2886 
force-limiting system. ${ }^{(10)}$ Furthermore, negative stiffness can be applied to a passive vibration isolator using negative stiffness, for example, a G-shaped beam isolator system. ${ }^{(11,12)}$ Therefore, we devised and fabricated a new passive vibration-free system using the post-buckling behavior of a tape-shaped Ti-Ni SMA element, as shown in Fig. $1 .^{(13)}$ This passive vibration isolator is constructed from a structure with quasi-zero stiffness by combining a positive-stiffness material (for example, a normal spring) and a negative-stiffness material (a tape-shaped SMA). The fabricated passive vibration isolator shows superior vibration removal characteristics. ${ }^{(13)}$ However, it requires a material with positive stiffness to offset the negative stiffness of the SMA element. Thus, control of the magnitude of the negative stiffness of the SMA element during post-buckling deformation is necessary for the practical use of this passive vibration isolator system.

In previous studies, we investigated the effect of the transformation temperature and Young's modulus on the post-buckling behavior of a tape-shaped SMA element by material testing and 3D finite element method (FEM) simulations. ${ }^{(14,15)}$ It was found that the magnitude of negative stiffness tends to have a maximum when the environmental temperature is near the Austenite finish temperature $\left(A_{f}\right)$, and the magnitude of negative stiffness increases with increasing difference between Young's modulus and the tangential stiffness during the martensitic transformation. However, the negative stiffness of the SMA element can be varied by modifying the dimensions of the SMA element. In this study, the effect of the thickness of a tape-shaped SMA element on the post-buckling behavior is investigated by FEM analysis.

\section{Materials and Methods}

Three-dimensional FEM simulations were conducted using ANSYS Workbench software to analyze the post-buckling behavior of a tape-shaped SMA element. Figure 2 illustrates the 3D model of the tape-shaped SMA element used in the software. The length and width of the

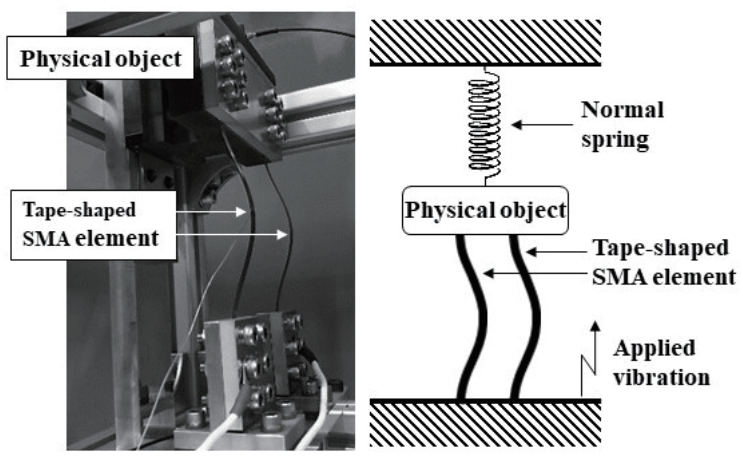

Fig. 1. Photograph and schematic drawing of the passive vibration-free system using the post-buckling behavior of a tape-shaped Ti-Ni SMA element. ${ }^{(13)}$

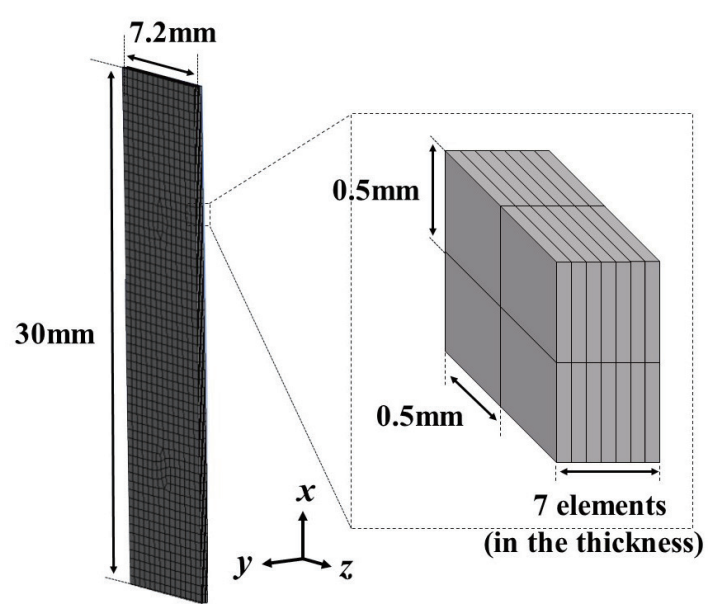

Fig. 2. Three-dimensional model of tape-shaped SMA element used in the software. 
model are 30 and $7.2 \mathrm{~mm}$, respectively. The size of one element in the $x$ and $z$ directions (length and width directions) is $0.5 \mathrm{~mm}$, and seven elements are arranged in the $y$ direction (thickness direction). The goal of this study is to investigate the effect of thickness on the post-buckling behavior. Therefore, the 3D FEM simulations are performed for SMA element thicknesses of 0.1, $0.3,0.5,0.7$, and $0.9 \mathrm{~mm}$.

Figure 3 shows the process of analysis of the post-buckling behavior of the tape-shaped SMA element using the software. In this study, we consider a four-step sequence during buckling deformation. In step 1, a $10 \mathrm{~N}$ horizontal force is applied to the center of the material with $0.15 \mathrm{~mm}$ displacement of the upper end of the material to induce buckling (referred to as a buckling displacement). In step 2, the horizontal force on the material center is removed. The buckled form is maintained because the $0.15 \mathrm{~mm}$ buckling displacement is retained. In step 3, the buckling displacement is increased from 0.15 to $3.0 \mathrm{~mm}$. Finally, the buckling displacement is removed in step 4. In this study, the relationship between the buckling displacement at the upper end of the material and the reaction force of the bottom end during steps 3 and 4 is investigated. In addition, steps 1 and 2 are excluded from the analysis results because the horizontal force applied to the center of the material is a disturbance.

Figure 4 shows the stress-strain curve of the material model inputted in the software, and Fig. 5 shows the relationship between the reaction force and buckling displacement numerically

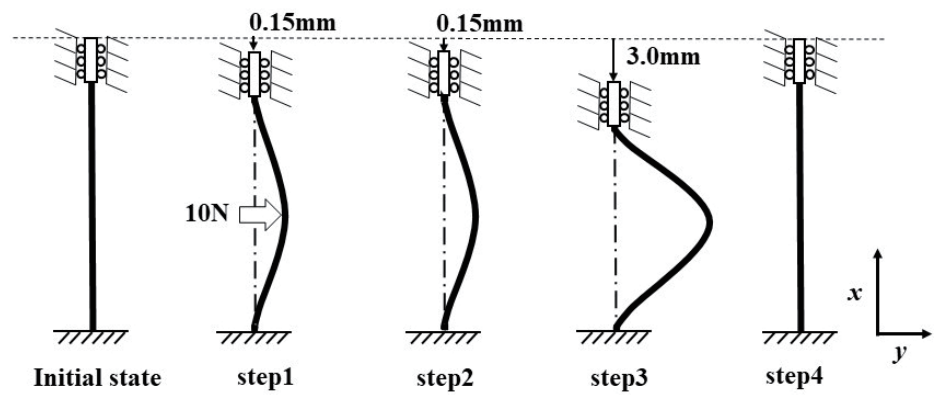

Fig. 3. Process of analysis of post-buckling behavior of tape-shaped SMA element using the software.

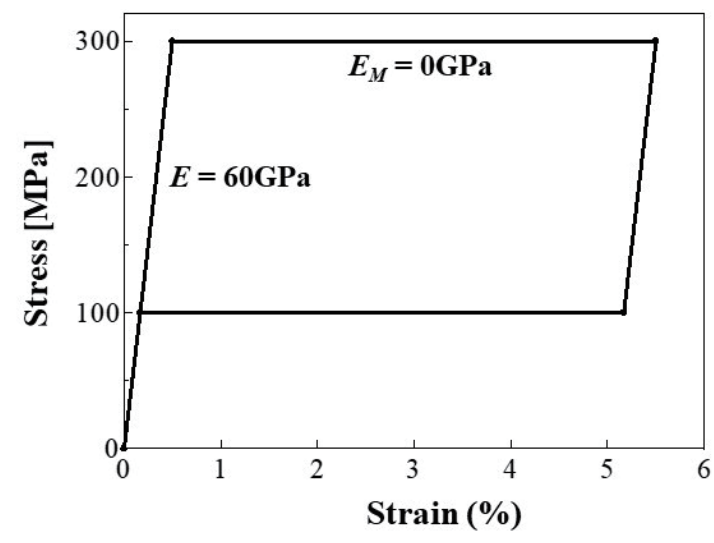

Fig. 4. Simulated stress-strain curve of the material model used in the software.

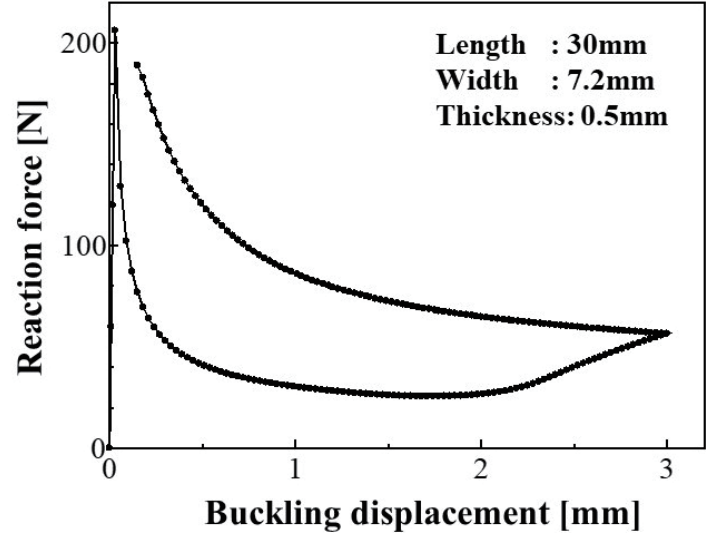

Fig. 5. Relationship between reaction force and buckling displacement numerically obtained using the material model. 
obtained using the material model. The martensite-induced stress $\left(\sigma_{M}\right)$ is $300 \mathrm{MPa}$, and the Young's modulus $(E)$ and tangential stiffness during the martensitic transformation $\left(E_{M}\right)$ of this material model are 60 and $0 \mathrm{GPa}$, respectively. According to Fig. 5, the negative stiffness of the SMA element during post-buckling deformation can be simulated by FEM software.

\section{Results and Discussion}

\subsection{Simulation of mechanical characteristics}

Figure 6 shows the numerically obtained relationship between the reaction force and buckling displacement of the tape-shaped SMA element for each thickness. Each numerical result shows negative stiffness during post-buckling deformation. In addition, the negative tangential stiffness (the absolute value of the stiffness) of the SMA elements appears to increase with increasing thickness. However, it is difficult to distinguish whether this tendency is due to the effect of the increased thickness or the increased buckling stress. Thus, the force is normalized with the buckling stress.

Figure 7 shows the numerically obtained relationship between the normalized reaction force and buckling displacement of the tape-shaped SMA element for each thickness, and Fig. 8 shows the relationship between the buckling displacement and tangential stiffness of the SMA element for each thickness. The tangential stiffness of the specimen with $0.1 \mathrm{~mm}$ thickness is positive as the buckling displacement increases to $2 \mathrm{~mm}$, above which it is negative. Other specimens show negative stiffness in the whole range of the buckling displacement. Furthermore, the tangential stiffness tends to converge to nearly zero with increasing buckling displacement. During buckling deformation, it is the bending stress that is most affected by the thickness variation. In addition, it is well known that an SMA transforms to the martensitic phase when the applied stress reaches $\sigma_{M}$, as shown in Fig. 4. Thus, we infer that the negative stiffness of the SMA element is caused by the variation of the bending stiffness in the specimen during post-buckling deformation, and the main factor causing the bending stiffness variation is

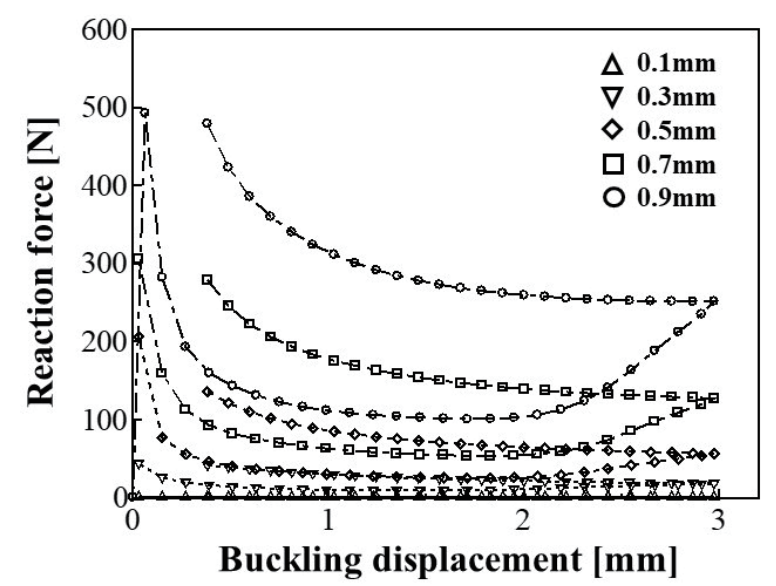

Fig. 6. Numerically obtained relationship between reaction force and buckling displacement of tape-shaped SMA element for each thickness. 


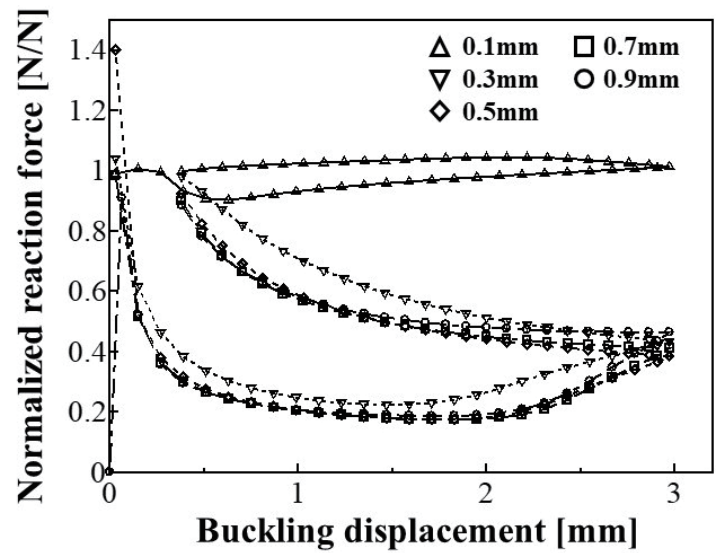

Fig. 7. Numerically obtained relationship between normalized reaction force and buckling displacement of tape-shaped SMA element for each thickness.

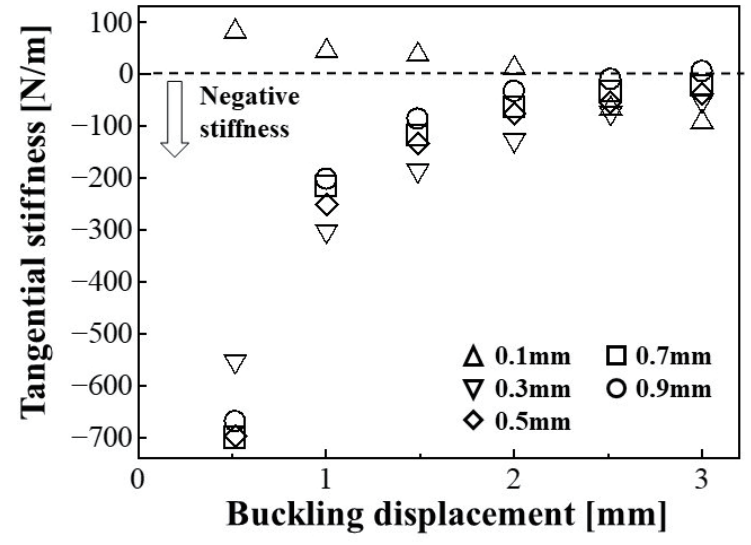

Fig. 8. Relationship between buckling displacement and tangential stiffness of SMA element for each thickness.

thought to be the martensitic transformation (the variation of Young's modulus due to the phase transformation). Therefore, the variation of the volume fraction of the martensitic phase during post-buckling deformation was calculated.

\subsection{Simulation of volume fraction of martensitic phase}

Figure 9 shows the numerically obtained relationship between the buckling displacement and the volume fraction of the martensitic phase. In this study, the volume fraction of the martensitic phase is defined as the percentage of node points with strain of more than $0.5 \%$. In the case of $0.1 \mathrm{~mm}$ thickness, the volume fraction of the martensitic phase is almost zero as the buckling displacement increases to $2 \mathrm{~mm}$, above which it increases. Meanwhile, the volume fraction of the martensitic phase of the other specimens increases abruptly up to a buckling displacement of $1 \mathrm{~mm}$, above which it increases gradually. Furthermore, the increase in the volume fraction of the martensitic phase appears to saturate above a buckling displacement of $2 \mathrm{~mm}$. These tendencies are in very good agreement with the relationship between buckling displacement and tangential stiffness shown in Fig. 8. From these results, we infer that the increase in the rate of increase of the volume fraction of the martensitic phase leads to the increase in the negative tangential stiffness of the SMA element. Therefore, we calculated the thickness dependences of the tangential stiffness and the rate of increase of the volume fraction of the martensitic phase when the buckling distance was $0.5 \mathrm{~mm}$. The results are shown in Fig. 10. To help us understand the results, the tangential stiffnesses in this figure are absolute values, and the result for the 0.1-mm-thick specimen is eliminated because this specimen does not show negative stiffness when the buckling distance is $0.5 \mathrm{~mm}$. The tangential stiffness tends to increase with the rate of increase of the volume fraction of the martensitic phase.

From this result, we consider that the tangential stiffness of the SMA element during postbuckling deformation depends on the rate of increase of the volume fraction of the martensitic phase during buckling deformation. In other words, the variation of the post-buckling behavior 


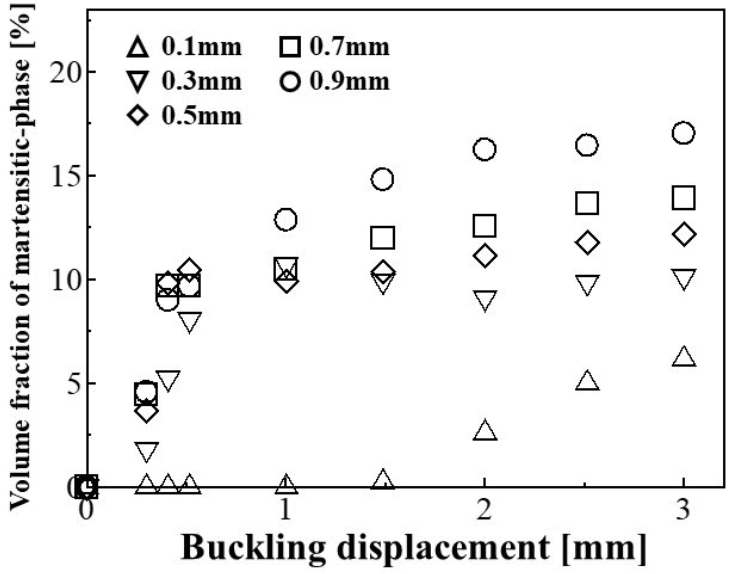

Fig. 9. Numerically obtained relationship between buckling displacement and volume fraction of martensitic phase.

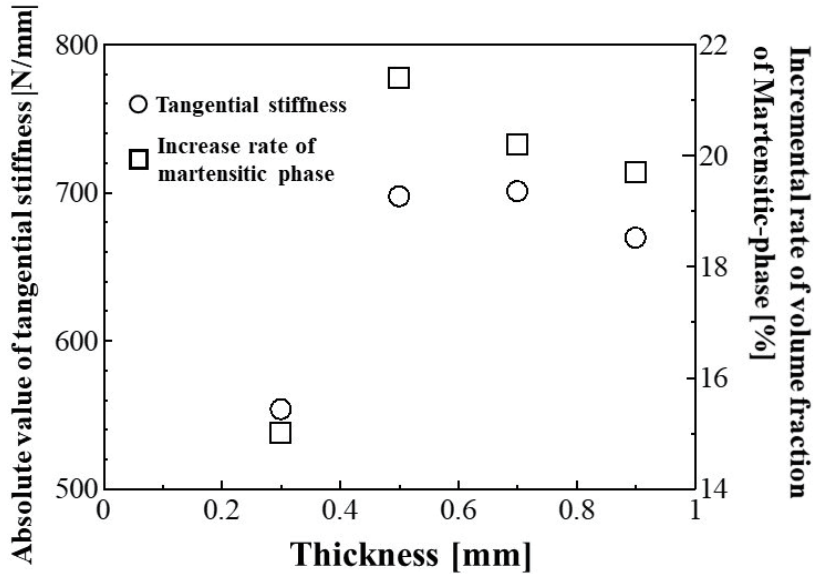

Fig. 10. Numerical results showing thickness dependences of the tangential stiffness and the rate of increase of the volume fraction of the martensitic phase when the buckling distance is $0.5 \mathrm{~mm}$.

with the thickness seems to be caused by the variation of the volume fraction of the martensitic phase induced by the fluctuation of the applied stress during post-buckling deformation.

\subsection{Validation analysis}

In a previous study, we concluded that the magnitude of the negative stiffness of an SMA element depends on the difference between Young's modulus and the tangential stiffness during the martensitic transformation. ${ }^{(15)}$ In this study, we consider that the tangential stiffness of the SMA element during post-buckling deformation depends on the variation of the volume fraction of the martensitic phase during buckling deformation. If the results of the previous study and this study are correct, we can then propose the following. For a fixed difference between Young's modulus $(E)$ and the tangential stiffness during martensitic transformation $\left(E_{M}\right)$, the variation of the volume fraction of the martensitic phase during post-buckling deformation should be the same. Therefore, we investigated the variation of the volume fraction of the martensitic phase during post-buckling deformation for various stress-strain curves with the same difference between $E$ and $E_{M}$ by numerical analysis.

Figure 11 shows the relationship between the reaction force and buckling displacement of a tape-shaped SMA element with a constant difference between $E$ and $E_{M}$ of $30 \mathrm{GPa}$ and an element thickness of $0.43 \mathrm{~mm}$. Figure 12 shows the relationship between the volume fraction of the martensitic phase during post-buckling deformation and the buckling displacement of the tape-shaped SMA element with a constant difference between $E$ and $E_{M}$. According to Fig. 12, the variation of the volume fraction of the martensitic phase during post-buckling deformation is approximately constant when the difference between $E$ and $E_{M}$ is constant. From these results, we conclude that the magnitude of the negative stiffness during the post-buckling of a tape-shaped SMA element depends on the variation of the volume fraction of the martensitic phase during buckling deformation. 


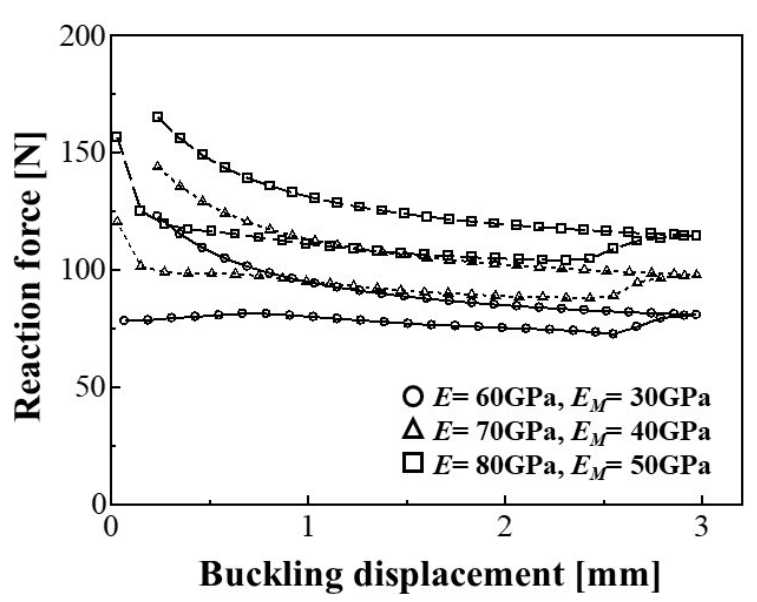

Fig. 11. Relationship between reaction force and buckling displacement of tape-shaped SMA element with constant difference between $E$ and $E_{M}$.

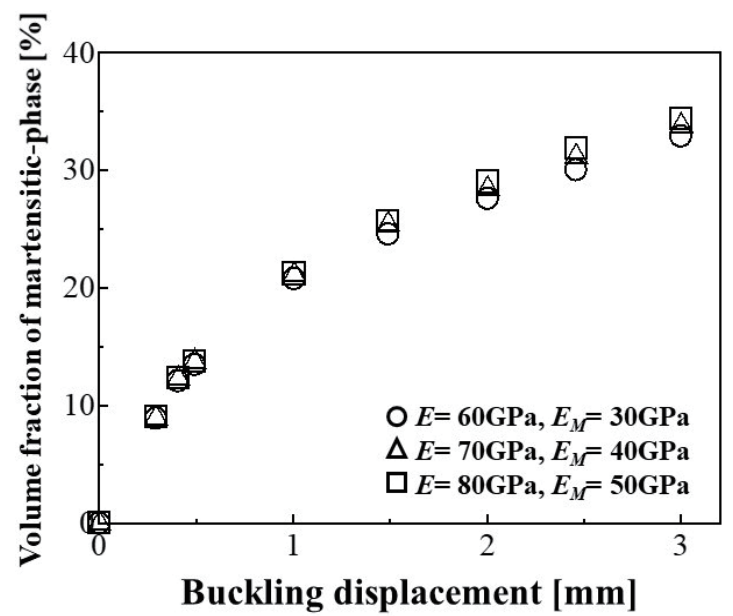

Fig. 12. Relationship between volume fraction of martensitic phase during post-buckling deformation and buckling displacement of tape-shaped SMA element with constant difference between $E$ and $E_{M}$.

\section{Conclusions}

For the purpose of developing a passive vibration-free system using the post-buckling behavior of an SMA element, the effect of the thickness on the post-buckling behavior of a tapeshaped SMA element was investigated by FEM analysis. The obtained results are summarized as follows:

(i) The magnitude of the negative stiffness (absolute value of negative tangential stiffness) during post-buckling deformation of the SMA element tends to increase with the thickness (decreasing slenderness ratio). In addition, the tangential stiffness tends to converge to nearly zero with increasing buckling displacement.

(ii) The volume fraction of the martensitic phase increases abruptly during the range that shows the negative stiffness. In addition, the increase in the volume fraction of the martensitic phase saturates as the tangential stiffness converges to nearly zero with increasing buckling displacement.

(iii) As a result, we consider that the tangential stiffness of an SMA element during postbuckling deformation depends on the increase in the volume fraction of the martensitic phase during buckling deformation. By numerical analysis, we found that the negative tangential stiffness tends to increase with the rate of increase of the volume fraction of the martensitic phase during post-buckling deformation, and the increase in the volume fraction of the martensitic phase during buckling deformation is almost constant when the post-buckling characteristic is almost constant.

(iv) From these results, we conclude that the magnitude of negative stiffness during the postbuckling of a tape-shaped SMA element depends on the variation of the volume fraction of the martensitic phase during buckling deformation. Moreover, the variation of the postbuckling behavior with the thickness is caused by the variation of the volume fraction 
of the martensitic phase due to the fluctuation of the applied stress during post-buckling deformation.

\section{Acknowledgments}

This work was supported by JSPS KAKENHI Grant Number 18K04025 [Grant-in-Aid for Scientific Research (C) (2018-2020)].

\section{References}

1 S. Miyazaki, Y. Ohmi, K. Otsuka, and T. Suzuki: J. Phys. 43 (1982) 255.

2 G. Rondelli, B. Vicentini, and A. Cigada: Corros Sci. 30 (1990) 805.

3 L. Yan and Y. Liu: Scripta Metall. 34 (1996) 195.

4 M. Kohl, K. D. Skrobanek, and S. Miyazaki: Sens. Actuators, A 72 (1999) 243.

5 S. Miyazaki, M. Hirano, and V. H. No: Mater. Sci. Forum 349-395 (2002) 467-474.

6 A. D. Johnson: Record of the 10th Intersociety Energy Conversion and Engineering Conference, Newark, DE (1975) 530-534.

7 T. Honma: J. Jpn. Soc. Mech. Eng. 87 (1984) 517.

8 M. S. Rahman, J. Qiu, and J. Tani: Int. J. Solid Struct. 380 (2001) 9253.

9 J. Pereiro-Barceló and J. L. Bonet: Constr. Build. Mater. 155 (2017) 348. https://doi.org/10.1016/ j.conbuildmat.2017.08.083

10 S. Noda: Proc. 2018 JSME Conf. Robotics and Mechatronics (2018) 1A1-H02.

11 T. Sasaki, T. Waters, and Y. Tsuji: Mech. Eng. J.2 (2015) 15. https://doi.org/10.1299/mej.15-00030

12 T. Sasaki and T. P. Waters: J. Phys. Conf. Series 744 (2016) 1. https://doi.org/10.1088/1742-6596/744/1/012224

13 T. Sasaki and Y. Kimura: Proc. 18th Asia Pacific Vibration Conf. (2019) 1-6.

14 H. Cho, T. Sasaki, and H. Hosoda: Proc. 3rd Int. Symp. Biomedical Engineering (2018) 64-65.

15 T. Ishii and H. Cho: Proc. SICE Life Engineering Symp. 2019 and ECTI Biomedical Engineering (2019) 1A13.

\section{About the Authors}

Takumi Ishii received his B.E. degree from The University of Kitakyushu, Japan, in 2019. He is currently enrolled in the Graduate School of Environmental Engineering, The University of Kitakyushu. His research interests are in the FEM analysis of post-buckling characteristics of shape memory alloy elements. (a9mba003@eng.kitakyu-u.ac.jp)

Hiroki Cho received his B.E., M.E., and Ph.D. degrees in engineering from the University of Tsukuba, Japan, in 2001, 2003, and 2006, respectively. From 2008 to 2013, he was an assistant professor at Oita University, Japan. Since 2013, he has been an associate professor at The University of Kitakyushu. His research interests are in applications using shape memory alloys. (h-cho@kitakyu-u.ac.jp)

Atsushi Urakawa received his B.E. degree from The University of Kitakyushu, Japan, in 2019. He is currently enrolled in the Graduate School of Environmental Engineering, The University of Kitakyushu. His research interests are in the FEM analysis of vibration characteristics of shape memory alloy elements. (a9mba007@eng.kitakyu-u.ac.jp) 
Takumi Sasaki received his M.Eng. and Dr.Eng. degrees from Kyushu University, Japan, in 1998 and 2001, respectively. He started his career as an assistant professor at The University of Kitakyushu, Japan, in 2001. From 2002 to 2005, he was a lecturer, and since 2005, he has been an associate professor at The University of Kitakyushu. His research interests are in mechanical vibration, vibration control, and passive vibration isolators. (sasa@kitakyu-u.ac.jp) 